\title{
Outbreak characteristics associated with identification of contributing factors to foodborne illness outbreaks
}

\author{
L. G. BROWN ${ }^{1 *}$, E. R. HOOVER ${ }^{2}$, C. A. SELMAN ${ }^{2}$, E. W. COLEMAN ${ }^{1}$ AND \\ H. SCHURZ ROGERS ${ }^{1}$ \\ ${ }^{1}$ National Center for Environmental Health, Centers for Disease Control and Prevention, Atlanta, Georgia, USA \\ ${ }^{2}$ National Environmental Health Association, Denver, Colorado, USA
}

Received 28 November 2016; Final revision 23 May 2017; Accepted 2 June 2017

\section{SUMMARY}

Information on the factors that cause or amplify foodborne illness outbreaks (contributing factors), such as ill workers or cross-contamination of food by workers, is critical to outbreak prevention. However, only about half of foodborne illness outbreaks reported to the United States' Centers for Disease Control and Prevention (CDC) have an identified contributing factor, and data on outbreak characteristics that promote contributing factor identification are limited. To address these gaps, we analyzed data from 297 single-setting outbreaks reported to CDC's new outbreak surveillance system, which collects data from the environmental health component of outbreak investigations (often called environmental assessments), to identify outbreak characteristics associated with contributing factor identification. These analyses showed that outbreak contributing factors were more often identified when an outbreak etiologic agent had been identified, when the outbreak establishment prepared all meals on location and served more than 150 meals a day, when investigators contacted the establishment to schedule the environmental assessment within a day of the establishment being linked with an outbreak, and when multiple establishment visits were made to complete the environmental assessment. These findings suggest that contributing factor identification is influenced by multiple outbreak characteristics, and that timely and comprehensive environmental assessments are important to contributing factor identification. They also highlight the need for strong environmental health and food safety programs that have the capacity to complete such environmental assessments during outbreak investigations.

Key words: Contributing factors, foodborne illness outbreaks, food safety, outbreak investigation, restaurant outbreaks.

\section{INTRODUCTION}

Foodborne illness is a significant problem in the USA. An estimated 48 million foodborne illnesses occur annually in the USA, resulting in approximately 128

\footnotetext{
* Author for correspondence: L. G. Brown, Centers for Disease Control and Prevention, 4770 Buford Highway, Mailstop F58, Atlanta, GA 30341, USA.

(Email: $\operatorname{lrg} 0 @$ cdc.gov)
}

000 hospitalizations and 3000 deaths $[1,2]$. Only a portion of these illnesses are associated with foodborne illness outbreaks (defined as two or more cases of a similar illness resulting from ingestion of a common food in the USA) [3]. However, investigations of outbreaks and analyses of data from those investigations provide important insights into the epidemiology of foodborne illness, such as the pathogens, foods, and environmental conditions that lead to 
illness. This information can be used to control and prevent future foodborne illness outbreaks. Because sporadic foodborne illnesses can have the same epidemiology as outbreaks, this information can also be used to reduce sporadic illnesses.

State and local public health departments provide epidemiological data to CDC from their foodborne illness outbreak investigations through the National Outbreak Reporting System (NORS) [4]. These data are typically collected and reported by epidemiology or communicable disease control programs within health departments, and include information on the etiologic agent, food, setting, and numbers of illnesses, hospitalizations, and deaths associated with the outbreak. Over time, these surveillance data have provided important information about foodborne illness and outbreaks, such as the identification of new and emerging foodborne agents, specific agent-food pairs, and the public health importance and effects of specific agents [3].

State and local public health departments also provide data to $\mathrm{CDC}$ on the factors contributing to foodborne illness outbreaks. These contributing factor data are typically collected by environmental health or food safety programs within health departments, who conduct the environmental health component of the outbreak investigation. Outbreak contributing factors are conditions that enable or amplify an outbreak, and fall into three categories: contamination (factors that contribute to the contamination of food with foodborne illness agents), proliferation (factors that contribute to the proliferation of microbial agents in food; proliferation could refer to an increase in the number of bacteria or the production of toxins), and survival (factors that contribute to the survival of foodborne illness agents after a process that should have eliminated or reduced them). For example, an ill worker infected with a foodborne agent can contaminate food with that agent while preparing it; that food, once ingested by customers, can cause an outbreak. This ill worker is a contamination contributing factor.

The U.S. Food and Drug Administration (FDA) and $\mathrm{CDC}$ have identified 32 contributing factors and grouped them according to whether they contribute to pathogen contamination, proliferation, or survival $[5,6]$. Information on outbreak contributing factors is critical to understanding and preventing foodborne illness and outbreaks. Environmental health/food safety programs can use these data to identify unsafe food preparation, cooking, holding, and storage practices that lead to outbreaks, and to develop messages and interventions to reduce or eliminate these practices. For example, CDC's analysis of the factors contributing to foodborne norovirus outbreaks identified infected food workers and bare-hand contact with ready-to-eat foods as predominant contamination issues, leading to specific recommendations for state and local governments and the restaurant industry on prevention of those contributing factors and, consequently, the outbreaks associated with them $[7,8]$. Other countries have also analyzed contributing factor data toward the goal of understanding and preventing outbreaks. For example, Gormley et al. [9] made recommendations for reducing cross contamination and improving hygiene in food service establishments, based on contributing factor data linked with outbreaks reported in England and Wales.

Despite their importance to prevention, contributing factors are identified for only about half of all foodborne illness outbreaks reported to CDC [10, 11], and data on outbreak characteristics that may promote contributing factor identification are limited. Given these data gaps, the purpose of the present study was to identify outbreak characteristics related to contributing factor identification.

\section{METHOD}

Data for this study were obtained from CDC's National Environmental Assessment Reporting System (NEARS) [12]. NEARS was developed to capture data from state and local health departments' environmental health component of foodborne illness outbreak investigations, as most of these data are not captured in NORS (the primary exception is contributing factor data, which is reported in both systems). This environmental health investigation component, often called an environmental assessment, is designed to thoroughly describe the environment in which the outbreak occurred, and to identify outbreak contributing factors and their antecedents. Environmental assessments typically involve the investigator visiting the outbreak establishment and interviewing the manager about establishment characteristics, such as food preparation policies and practices, and employee practices that may have contributed to the outbreak. They also typically involve a review of the processes used in the production of food items suspected to be linked to the outbreak, and observations of employee food preparation practices. Once these, and all other outbreak investigation activities are complete, environmental health staff make a contributing factor 
determination based on a critical review of the accumulated environmental health and epidemiological information gathered in the investigation.

NEARS was developed by the Environmental Health Specialists Network (EHS-Net), a CDCfunded network of environmental health specialists and epidemiologists from CDC, FDA, the U.S. Department of Agriculture, and several state and local health departments [13]. EHS-Net developed NEARS because the data collected during outbreak investigation environmental assessments is important to prevention - it can be used to support public health regulators' efforts to respond more effectively to foodborne illness outbreaks and to prevent foodborne illness outbreaks [14]. For example, the data collected on food safety policies can be used to identify and promote food safety policies that are related to smaller or fewer outbreaks, and the data collected on environmental health investigation characteristics can be used to identify and improve gaps in investigation practices. Despite the importance of these environmental health data to prevention, they have not been collected and analyzed at a national level. Thus, EHS-Net developed and launched NEARS.

NEARS was piloted from 2009 to 2013. During this time period, 11 state and local jurisdictions (California; County of San Mateo, California; Connecticut; Georgia; Minnesota; New York City, New York; New York; Oregon; Rhode Island; Tennessee; and Wisconsin) reported environmental assessment data from at least one outbreak to NEARS. For this paper, the following NEARS pilot data variables were analyzed: whether a food was linked with the outbreak, number of outbreak locations, and characteristics of establishments linked to outbreaks (establishment type, menu type, food preparation process type, whether the establishment served raw or undercooked food, ownership type, whether any meals were prepared off-site, and number of meals served daily). NEARS also collects data on environmental component of the investigation itself; we analyzed the following investigation data for this paper: number of days it took to contact the establishment to schedule an environmental assessment and number of establishment visits it took to complete the environmental assessment. Data on the outbreak etiologic agent for outbreaks reported to NEARS were obtained from NORS.

We grouped the factors of interest into three categories: outbreak characteristics (e.g., agent identification), outbreak establishment characteristics (e.g., establishment and menu type), and outbreak investigation characteristics (e.g., number of days it took to schedule the environmental assessment in the establishment). We conducted descriptive analyses of outbreak, outbreak establishment, and outbreak investigation characteristics. We also conducted simple logistic regression analyses to examine the strength of the relationships between these characteristics and contributing factor identification. Given the exploratory nature of the analyses, relationships significant at $P \leqslant 0 \cdot 10$ were deemed of interest.

\section{RESULTS}

\section{Outbreak characteristics}

Etiologic agents and food vehicles (Table 1)

From 2009 to 2013, 319 outbreaks were reported to NEARS. Of these, 297 (93.1\%) were single-setting outbreaks (i.e., outbreaks in which the agent exposure occurred in only one physical location; e.g., one restaurant); this paper focuses only on these singlesetting outbreaks. For $70.7 \%$ of these outbreaks, a primary etiologic agent was identified. Of these outbreaks, $76.7 \%$ had a confirmed agent (agent is laboratory-confirmed, as determined by NORS laboratory and clinical guidelines [15]) and 23.3\% had a suspected agent (agent is not confirmed by the NORS guidelines). Of outbreaks with a primary agent identified, most were caused by viruses $(68 \cdot 1 \%)$, followed by bacteria $(26 \cdot 2 \%)$, and toxins $(5 \cdot 7 \%)$. A food vehicle was identified in $55.9 \%$ of outbreaks.

\section{Contributing factors (Table 1)}

For $65 \cdot 3 \%$ (194) of outbreaks, at least one contributing factor was identified and reported. Of these outbreaks, $22 \cdot 2 \%$ (43) had more than one contributing factor; 267 contributing factors were identified altogether. Of the 194 outbreaks with contributing factors, $85.1 \%$ had at least one contamination factor, $19 \cdot 6 \%$ had at least one proliferation factor, and 10.3\% had at least one survival factor.

Of the 101 viral outbreaks with at least one identified contributing factor, $100.0 \%$ had a contamination factor, none had a proliferation factor, and $2.0 \%$ (2) had a survival factor. Of the 40 bacterial outbreaks with at least one identified contributing factor, $68 \%$ (27) had a contamination factor, $45 \%$ (18) had a proliferation factor, and $27 \cdot 5 \%$ (11) had a survival factor. All 12 toxin outbreaks had at least one identified 
Table 1. Characteristics of outbreaks, outbreak establishments, and outbreak investigations, single setting outbreaks - National Environmental Assessment Reporting System (NEARS), 2009-2013 ${ }^{a}$

\begin{tabular}{|c|c|c|}
\hline & $n$ & $\%$ \\
\hline \multicolumn{3}{|l|}{ Outbreak characteristics } \\
\hline \multicolumn{3}{|l|}{ Primary etiologic agent identified $(N=297)$} \\
\hline Yes & 210 & $70 \cdot 7$ \\
\hline No & 87 & $29 \cdot 3$ \\
\hline \multicolumn{3}{|l|}{ Outbreak type $(N=210)$} \\
\hline Viral & 143 & $68 \cdot 1$ \\
\hline Bacterial & 55 & $26 \cdot 2$ \\
\hline Toxin & 12 & $5 \cdot 7$ \\
\hline \multicolumn{3}{|l|}{ Food vehicle identified $(N=270)$} \\
\hline Yes & 151 & $55 \cdot 9$ \\
\hline No & 119 & $44 \cdot 1$ \\
\hline \multicolumn{3}{|l|}{ Contributing factor identified $(N=297)$} \\
\hline Yes & 194 & $65 \cdot 3$ \\
\hline No & 103 & $34 \cdot 7$ \\
\hline \multicolumn{3}{|l|}{ Contributing factor type $(N=194)^{\mathrm{b}}$} \\
\hline Contamination & 165 & $85 \cdot 1$ \\
\hline Proliferation & 38 & $19 \cdot 6$ \\
\hline Survival & 20 & $10 \cdot 3$ \\
\hline \multicolumn{3}{|l|}{ Outbreak establishment characteristics } \\
\hline \multicolumn{3}{|l|}{ Establishment type $(N=297)$} \\
\hline Restaurant & 259 & $87 \cdot 2$ \\
\hline Caterer & 5 & 1.7 \\
\hline Nursing home & 4 & $1 \cdot 4$ \\
\hline Restaurant in a supermarket & 4 & $1 \cdot 4$ \\
\hline Camp & 3 & $1 \cdot 0$ \\
\hline Workplace cafeteria & 3 & $1 \cdot 0$ \\
\hline Grocery store & 2 & $0 \cdot 7$ \\
\hline School foodservice & 2 & $0 \cdot 7$ \\
\hline Other & 15 & $5 \cdot 1$ \\
\hline \multicolumn{3}{|l|}{ Menu type $(N=297)$} \\
\hline American & 180 & $60 \cdot 6$ \\
\hline International or ethnic & 117 & $39 \cdot 4$ \\
\hline \multicolumn{3}{|l|}{ Establishment food preparation process type $(N=297)$} \\
\hline $\begin{array}{l}\text { Complex - a food item requires a kill step and includes holding beyond same day } \\
\text { service or some combination of holding, cooling, re-heating, and freezing }\end{array}$ & 253 & $85 \cdot 2$ \\
\hline Cook serve $-\mathrm{a}$ food item is prepared for same day service and involves a kill step & 26 & $8 \cdot 7$ \\
\hline Prep serve - all food items are prepared and served without a kill step & 18 & $6 \cdot 1$ \\
\hline \multicolumn{3}{|l|}{ Establishment serves raw or undercooked food $(N=297)$} \\
\hline Yes & 82 & $27 \cdot 6$ \\
\hline No & 215 & $72 \cdot 4$ \\
\hline \multicolumn{3}{|l|}{ Ownership type $(N=267)$} \\
\hline Chain & 82 & $30 \cdot 7$ \\
\hline Independent & 185 & $69 \cdot 3$ \\
\hline \multicolumn{3}{|l|}{ Meal preparation location $(N=266)$} \\
\hline All meals prepared on location & 234 & $88 \cdot 0$ \\
\hline Meals fully or partially prepared at another location & 32 & $12 \cdot 0$ \\
\hline \multicolumn{3}{|l|}{ Approximate number of meals served daily $(N=254)$} \\
\hline $1-150$ & 84 & $33 \cdot 1$ \\
\hline$>150$ & 170 & $66 \cdot 9$ \\
\hline \multicolumn{3}{|l|}{ Investigation characteristics } \\
\hline \multicolumn{3}{|l|}{ Time to contact outbreak establishment to schedule an environmental assessment $(N=283)$} \\
\hline Same day & 212 & $74 \cdot 9$ \\
\hline $1-5$ days & 61 & $21 \cdot 6$ \\
\hline 6-27 days & 10 & $3 \cdot 5$ \\
\hline
\end{tabular}


Table 1 (cont.)

\begin{tabular}{lrr}
\hline \hline & $n$ & $\%$ \\
\hline Number of visits made to outbreak establishment to complete the & & \\
environmental assessment $(N=285)$ & 133 & $46 \cdot 7$ \\
1 or 2 & 152 & $53 \cdot 3$ \\
$\geqslant 3$
\end{tabular}

${ }^{\text {a }}$ Denominators vary because of missing data for the explanatory variables.

${ }^{\mathrm{b}}$ Percentages add to more than 100 because outbreaks could have more than one contributing factor.

contributing factor; $83 \cdot 3 \%$ (10) had a contamination factor, $25 \cdot 0 \%$ (3) had a proliferation factor, and none had a survival factor.

\section{Outbreak establishment characteristics (Table 1)}

Most NEARS outbreaks occurred in restaurants $(87 \cdot 2 \%)$, in establishments with American menus $(60 \cdot 6 \%)$, in establishments with complex food preparation processes (processes that require a kill step and include holding beyond same day service or some combination of holding, cooling, re-heating, and freezing) $(85 \cdot 2 \%)$, and in independently owned establishments $(69 \cdot 3 \%)$. Most also served raw or undercooked food $(72 \cdot 4 \%)$, prepared all meals on location $(88.0 \%)$, and served more than 150 meals daily $(66 \cdot 9 \%)$.

\section{Outbreak investigation characteristics (Table 1)}

NEARS sites reported the date they first identified an establishment associated with an outbreak for an environmental assessment and the date they first contacted the establishment. Most (74.9\%) outbreak establishments were contacted the same day they were identified for an environmental assessment, $21.6 \%$ were contacted within 5 days of their identification for an environmental assessment, and 3.5\% were contacted after 6 or more days of their identification for an environmental assessment. NEARS sites also reported the number of visits they made to each outbreak establishment to complete the environmental assessment; $46.7 \%$ needed one or two establishment visits for environmental assessment completion, and $53 \cdot 3 \%$ required three or more establishment visits.

\section{Characteristics associated with outbreak contributing factor identification (Table 2)}

Simple logistic regression analyses identified one outbreak characteristic and two outbreak establishment characteristics associated with contributing factor identification. Outbreaks with identified agents had greater odds of having an identified contributing factor than did outbreaks with no identified agents $(\mathrm{OR}=3 \cdot 27,90 \% \mathrm{CI}=2 \cdot 10-5 \cdot 10)$. Outbreaks in establishments that prepared all meals on location had greater odds of having an identified contributing factor than did outbreaks in establishments that fully or partially prepared meals at another location (e.g., a commissary) $(\mathrm{OR}=2 \cdot 14,90 \% \mathrm{CI}=1 \cdot 14-4 \cdot 00)$. Outbreaks in establishments that served more than 150 meals daily had greater odds of having an identified contributing factor than did outbreaks in establishments that served fewer meals daily $(\mathrm{OR}=1 \cdot 78,90 \%$ $\mathrm{CI}=1 \cdot 12-2 \cdot 81$ ).

Simple logistic regression analyses also revealed that both outbreak investigation characteristics were associated with outbreak contributing factor identification. Outbreaks in which investigators contacted the outbreak establishment on the same day they identified the establishment for an environmental assessment had greater odds of having an identified contributing factor than did outbreaks in which sites took a day or longer to contact the outbreak establishment $(\mathrm{OR}=1 \cdot 86,90 \% \mathrm{CI}=1 \cdot 16-2 \cdot 97)$. Outbreaks in which environmental assessment completion took three or more visits to the outbreak establishment had greater odds of having an identified contributing factor than did outbreaks in which environmental assessment completion took only one or two visits to the outbreak establishment $(\mathrm{OR}=1 \cdot 87,90 \% \mathrm{CI}=$ $1 \cdot 06-3 \cdot 31)$.

\section{DISCUSSION}

The findings from this study provide valuable and novel information about contributing factor identification, an important goal of outbreak investigations. This study identified outbreak, outbreak establishment, and outbreak investigation characteristics 
Table 2. Outbreak, outbreak establishment, and outbreak investigation characteristics associated with contributing factor identification, single-setting outbreaks - National Environmental Assessment Reporting System (NEARS), $2009-2013^{a}$

\begin{tabular}{|c|c|c|}
\hline & OR $(90 \% \mathrm{CI})$ & $P$ value \\
\hline \multicolumn{3}{|l|}{ Outbreak characteristics } \\
\hline \multicolumn{3}{|l|}{ Primary etiologic agent identified $(N=291)$} \\
\hline Yes & $3 \cdot 27(2 \cdot 10-5 \cdot 10)$ & $<0 \cdot 001$ \\
\hline No & - & - \\
\hline \multicolumn{3}{|l|}{ Outbreak type $(N=195)$} \\
\hline Viral & $0 \cdot 80(0 \cdot 44-1 \cdot 47)$ & 0.547 \\
\hline Bacterial & - & - \\
\hline \multicolumn{3}{|l|}{ Toxin ${ }^{b}$} \\
\hline \multicolumn{3}{|l|}{ Food vehicle identified $(N=267)$} \\
\hline Yes & $1 \cdot 34(0 \cdot 87-2 \cdot 05)$ & 0.261 \\
\hline No & - & - \\
\hline \multicolumn{3}{|l|}{ Outbreak establishment characteristics } \\
\hline \multicolumn{3}{|l|}{ Establishment type $(N=291)$} \\
\hline Restaurant & $1 \cdot 38(0 \cdot 76-2 \cdot 50)$ & 0.372 \\
\hline Other & - & - \\
\hline \multicolumn{3}{|l|}{ Menu type $(N=291)$} \\
\hline American & $0 \cdot 91(0 \cdot 60-1 \cdot 38)$ & 0.712 \\
\hline Other & - & - \\
\hline Establishment food preparation process type $(N=291)$ & & 0.572 \\
\hline Complex & $0 \cdot 76(0 \cdot 31-1 \cdot 86)$ & 0.613 \\
\hline Cook serve & $0 \cdot 52(0 \cdot 18-1 \cdot 55)$ & 0.328 \\
\hline Prep serve & - & - \\
\hline \multicolumn{3}{|l|}{ Establishment serves raw or undercooked food $(N=291)$} \\
\hline Yes & - & - \\
\hline No & $0 \cdot 76(0 \cdot 48-1 \cdot 21)$ & 0.327 \\
\hline \multicolumn{3}{|l|}{ Ownership type $(N=262)$} \\
\hline Chain & $1 \cdot 36(0 \cdot 85-2 \cdot 19)$ & 0.282 \\
\hline Independent & - & - \\
\hline \multicolumn{3}{|l|}{ Meal preparation location $(N=261)$} \\
\hline All meals prepared on location & $2 \cdot 14(1 \cdot 14-4 \cdot 00)$ & 0.046 \\
\hline Meals fully or partially prepared at another location & - & - \\
\hline \multicolumn{3}{|l|}{ Approximate number of meals served daily $(N=249)$} \\
\hline $1-150$ & - & - \\
\hline$>150$ & $1 \cdot 78(1 \cdot 12-2 \cdot 81)$ & 0.039 \\
\hline \multicolumn{3}{|l|}{ Outbreak investigation characteristics } \\
\hline \multicolumn{3}{|l|}{ Time to contact $(N=277)$} \\
\hline Same day & $1 \cdot 86(1 \cdot 16-2 \cdot 97)$ & 0.030 \\
\hline $1-5$ days $^{\mathrm{c}}$ & - & - \\
\hline $6-27$ days $^{c}$ & - & - \\
\hline \multicolumn{3}{|c|}{ Number of visits made to complete environmental assessment $(N=285)$} \\
\hline 1 or 2 & - & - \\
\hline$\geqslant 3$ & $1 \cdot 87(1 \cdot 06-3 \cdot 31)$ & 0.070 \\
\hline
\end{tabular}

${ }^{\mathrm{a}}$ Denominators vary because of missing data for the explanatory variables.

${ }^{\mathrm{b}}$ Because of small cell size, the toxin category was not included in this analysis; odds ratio is 'viral' vs. 'bacterial.'

' Because of small cell size, these two categories were collapsed for odds ratio analyses; odds ratio is 'same day' vs. 'one or more days.'

that may promote outbreak contributing factor identification. These characteristics include: etiologic agent identification, exclusive on-site meal preparation, more meals served daily, contact with outbreak establishments soon after they are linked with an outbreak, and multiple establishment visits for environmental assessment completion.

The finding that contributing factor identification was more likely when agents had been identified is consistent with research indicating that outbreak 
investigators find that knowledge of the agent facilitates contributing factor identification [16]. However, it is also possible that both agent and contributing factor identification are primarily dependent on the quality and intensity of the investigation, rather than contributing factor identification being dependent on agent identification. More research is needed on this topic.

The finding that contributing factor identification was more likely in establishments that prepared all their food on location may reflect a lack of environmental assessment data from the off-site locations in which food was prepared. If investigators do not collect environmental assessment data from off-site preparation locations, they may not have data important to contributing factor identification. The finding that contributing factor identification was more likely for outbreaks that occurred in establishments serving more meals daily is interesting. Investigators might have more opportunity to observe and interview workers at establishments that prepare many meals, and thus to conduct a more comprehensive environmental assessment. Alternatively, establishments that serve more meals might have better organization and consequent documentation, providing investigators with information needed to conduct a more comprehensive environmental assessment. It is also possible that outbreaks involving restaurants serving more meals may involve larger numbers of ill people; these larger numbers may lead to additional information about the outbreak, which may help with contributing factor identification.

The links between the investigation characteristics of quickly-initiated and thorough environmental assessments and contributing identification suggest that timely, rapid, and comprehensive environmental assessments are important to contributing factor identification. These links also highlight the need for strong environmental health and food safety programs that have the capacity to quickly complete such environmental assessments during outbreak investigations.

This study also provides valuable and novel data on characteristics of the environmental health component of outbreak investigations; these data highlight investigation practice strengths and weaknesses. Most NEARS sites quickly (within a day) contacted suspected outbreak establishments after they were identified for an environmental assessment. This is a positive finding; outbreak investigation experts recommend that environmental assessments be initiated as early in the investigation as possible [17]. However, for a quarter of outbreaks, NEARS sites took longer, sometimes substantially longer, to contact suspected outbreak establishments. These findings are concerning. Circumstances in an establishment can change substantially in a week, particularly when the establishment has been linked with an outbreak. The effectiveness of environmental assessments in identifying contributing factors is likely reduced when conducted more than $24-48 \mathrm{~h}$ after an establishment is linked with an outbreak. The data reported here also show that for many outbreaks, environmental assessment completion took several visits to the outbreak establishment. These data suggest that environmental assessments can require an investment of time and resources.

Identifying outbreak contributing factors is a key part of understanding and preventing foodborne illness and outbreaks. We found that contributing factors were identified for outbreaks reported to NEARS more than half the time; this is positive. However, it is critical for environmental health programs and investigators to work to identify contributing factors for all outbreaks. Our findings identify some program activities, such as timely and comprehensive environmental assessments, that might help in achieving this goal. Additionally, CDC provides free, high-quality training on conducting environmental assessments during outbreak investigations that can improve investigators' ability to identify contributing factors [18].

This study also provides novel data on the characteristics of outbreak establishments. These data give context to the environment in which outbreaks occur and could help focus prevention efforts. For example, the proportion of NEARS outbreak establishments with complex food preparation processes $(85 \%)$ is higher than we might expect, given that other studies have found the proportion of establishments with complex food preparation processes to be about 50\% (CDC/Environmental Health Specialists Network [EHS-Net], unpublished data from the EHS-Net restaurant cooling practices study; [19]). This disparity suggests that outbreaks might be more likely to occur in establishments with complex preparation processes than in establishments with simpler preparation processes. Data like these will facilitate the development of hypotheses for studies on the characterization of food service establishment outbreaks and highlight the potential value of NEARS data.

NEARS became fully operational in April 2014 and, as of May 2017, had 25 participating sites. The analyses reported here should be replicated using 
data reported into this fully operational system. Also, the fully operational NEARS collects more data from the environmental health component of outbreak investigations than are reported here, including data on how contributing factors are identified and outbreak establishment food safety policies and practices (e.g., kitchen manager certification policies, employee health policies). Future analyses will explore these data and their implications for outbreak investigation and prevention.

The findings in this paper are subject to several limitations. First, the findings are based on data reported by a limited number of sites. Although the overall pattern of outbreak data reported into NEARS is consistent with the overall pattern of outbreak data reported into NORS (the majority of outbreaks with identified agents reported into both NEARS and NORS were viral and were restaurantassociated [8]), the NEARS outbreaks are a subset of NORS outbreaks, and thus, might not represent all U.S. outbreaks. Second, some of the sites reporting data into NEARS received funding from CDC to do so; investigations conducted and data reported by these sites might not be representative of those of nonfunded sites. Third, not all outbreaks are identified and investigated by state and local investigators. The extent to which the outbreaks reported into NEARS represent all outbreaks that occurred in the NEARS sites during the reporting period is unknown. Fourth, these data are correlational, and do not allow us to determine with certainty the direction of the relationships observed between outbreak, outbreak establishment, and outbreak investigation characteristics and contributing factor identification.

There are also some limitations associated with contributing factor data. Primarily, methods used to identify contributing factors likely vary by investigating jurisdictions. For example, research has indicated that some jurisdictions do not base their contributing factor determination on epidemiologic or environmental health data. See Gould et al. [3] for a more extensive discussion of contributing factor data limitations.

The data presented here provide valuable and novel information about contributing factor identification, an important component of outbreak investigations, and about outbreak establishment and investigation characteristics. These data also highlight the potential of NEARS data to contribute to our understanding of the causes of foodborne illness outbreaks.

\section{ACKNOWLEDGMENTS}

This publication is based in part on data collected and provided by the Centers for Disease Control and Prevention's (CDC) Environmental Health Specialists Network (EHS-Net), which is supported by a CDC grant award funded under CDC-RFAEH05-013. We thank the EHS-Net site staff who assisted with NEARS development, and the NEARS site staff who collected and entered their outbreak data. The findings and conclusions in this report are those of the authors and do not necessarily represent the views of CDC or the Agency for Toxic Substances and Disease Registry.

\section{REFERENCES}

1. Scallan E, Griffin P, Angulo F, Tauxe R, Hoekstra R. Foodborne illness acquired in the United States - unspecified agents. Emerging Infectious Diseases 2011; 17: 16-22.

2. Scallan E, Hoekstra M, Angulo F, Tauxe R, Widdowson MA, Roy S, Jones J, Griffin P. Foodborne illness acquired in the United States - major pathogens. Emerging Infectious Diseases 2011; 17: 7-15.

3. Gould H, Walsh K, Vieira A, Herman K, Williams I, Hall A, Cole D. Surveillance for foodborne disease outbreaks - United States, 1998-2008. Morbidity and Mortality Weekly Report 2013; 62: 1-34.

4. CDC. Foodborne Outbreak Tracking and Reporting. Atlanta, GA: US Department of Health and Human Services, CDC, 2016b. Available at: https://www.cdc. gov/foodsafety/fdoss/reporting/index.html. Accessed 7 March 2017.

5. Bryan F, Guzewich J, Todd E. Surveillance of foodborne diseases III. Summary and presentation of data on vehicles and contributory factors: their value and limitations. Journal of Food Protection 1997; 60: 701-14.

6. CDC. National Outbreak Reporting System (NORS) Guidance. Atlanta, GA: US Department of Health and Human Services, CDC, 2014a. Available at: http:// www.cdc.gov/nors/pdf/NORS-Guidance_FINAL508c. pdf. Accessed 7 March 2017.

7. CDC. Vital Signs: Preventing Norovirus Outbreaks. Atlanta, Georgia: US Department of Health and Human Services, CDC, 2014b. Available at: http:// www.cdc.gov/vitalsigns/norovirus/index.html. Accessed 7 March 2017.

8. Hall A, Wikswo M, Pringle K, Gould H, Parashar U. Vital signs: foodborne norovirus outbreaks - United States, 2009-2012. Morbidity and Mortality Weekly Report 2014; 63: 491-495.

9. Gormley F, Little C, Rawal N, Gillespie I, Lebaigue S, Adak G. A 17-year review of foodborne outbreaks: describing the continuing decline in England and Wales (1992-2008). Epidemiology \& Infection 2011; 139: 688-699. 
10. CDC. Surveillance for Foodborne Disease Outbreaks, United States, 2013, Annual Report. Atlanta, Georgia: US Department of Health and Human Services, CDC, 2015. Available at: https://www.cdc.gov/foodsafety/ pdfs/foodborne-outbreaks-annual-report-2014-508.pdf. Accessed 7 March 2017.

11. CDC. Surveillance for Foodborne Disease Outbreaks, United States, 2014, Annual Report. Atlanta, Georgia: US Department of Health and Human Services, CDC, 2016. Available at: https://www.cdc.gov/foodsafety/ pdfs/foodborne-disease-outbreaks-annual-report-2013508c.pdf. Accessed 7 March 2017.

12. CDC. National Environmental Assessment Reporting System (NEARS). Atlanta, GA: US Department of Health and Human Services, CDC, 2015. Available at: https://www.cdc.gov/nceh/ehs/nears/index.htm. Accessed 7 March 2017.

13. CDC. Environmental Health Specialists Network (EHSNet). Atlanta, GA: US Department of Health and Human Services, CDC, 2016. Available at: https:// www.cdc.gov/nceh/ehs/ehsnet/. Accessed 7 March 2017.

14. Selman C. Improving foodborne disease prevention. Journal of Environmental Health 2010; 73: 28-29.

15. CDC. Guide to Confirming an Etiology in Foodborne Disease Outbreak. Atlanta, GA: US Department of
Health and Human Services, CDC, 2017. Available at: https://www.cdc.gov/foodsafety/outbreaks/investigatingoutbreaks/confirming_diagnosis.html. Accessed 7 March 2017.

16. Selman C, Green L. Environmental health specialists' self-reported foodborne illness outbreak investigation practices. Journal of Environmental Health 2008; 70: 16-21.

17. Selman C, Guzewich J. Public health measures: environmental assessment in outbreak investigations. In: Motarjemi Y, ed. Encyclopedia of Food Safety. Waltham, MA: Academic Press, 2014, vol. 4, pp. 98106. Available at: https://www.cdc.gov/nceh/ehs/nears/ docs/ea-encyclopedia-foodsafety.pdf. Accessed 7 March 2017.

18. Centers for Disease Control and Prevention. E-Learning on Environmental Assessment of Foodborne Illness Outbreaks. Atlanta, GA: US Department of Health and Human Services, CDC, 2015a. Available at: https://www.cdc.gov/nceh/ehs/elearn/ea_fio/index.htm. Accessed 7 March 2017.

19. Radke T, Brown L, Hoover E, Faw B, et al. Food allergy knowledge and attitudes of restaurant managers and staff: an EHS-Net study. Journal of Food Protection 2016; 79: 1588-1598. 